\title{
ReLiability of Diagnostic TESTS IN Rotator Cuff Muscle Pathology
}

\begin{abstract}
Background: Several tests to assist it in the diagnoses of rotator cuff impairment have been described in the literature but controversy still exists as to the accuracy of these tests. A study was therefore conducted to determine the reliability of the rotator cuff muscle tests (empty can, full can, lift off and external rotation) as a diagnostic tool.

Methodology: Fifty three patients experiencing shoulder pain were assessed using manual muscle tests (empty can; full can; lift off and external rotation tests). Both pain and weakness were recorded using numerical scales adapted from tests performed by Itoi et al, (1999). These results were compared to

\section{Sandenbergh R, (MphysT, UP) ${ }^{1}$} Marais A, (MphysT, UP) ${ }^{1}$

${ }^{1}$ Department of Physiotherapy, Faculty of Health Sciences, University of Pretoria. ultrasonic diagnoses made by a surgeon. Informed consent was obtained and anonymity was ensured for all participants. Results: A test was false positive when ultrasonic diagnosis indicated no tear in the muscle (although oedema or calcification may have been present), but the manual muscle test was positive regarding pain and weakness. A test on the other hand was false negative when the ultrasonic diagnosis indicated a muscle tear but the manual muscle tests indicated no pain or muscle weakness. Reliability was tested using sensitivity and specificity tests. The sensitivity of all four tests was high (80\%), but the specificity was low (20\% to 40\%), implying that a large number of false positive diagnoses can be made. The major contributors to the false positive results were sub-acromial sub-deltoid bursitis and a decreased acromio-humeral space. When considering pain alone for a positive result the correlation increased a little, however, taking both pain and muscle weakness into account, the correlation increased even more.

Conclusion: The manual muscle tests were not as reliable as expected, but concurrent pathologies may be the main factor influencing the results of the tests. The combination of muscle strength and pain could be recommended as criteria for a positive test. The empty can and full can tests could both be recommended in predicting a torn supraspinatus tendon, as they were equally sensitive
\end{abstract}

KEY WORDS: DIAGNOSTIC TOOL, ROTATOR CUFF MUSCLES.

\section{BACKGROUND AND PURPOSE}

Thomson et al. (1996) in their study on cadavers' shoulders, found that up to $80 \%$ had a full thickness tear of the rotator cuff and that the incidence increased with the age of the person. It is therefore necessary to accurately diagnose this condition to be able to treat it efficiently.

Several tests have been identified to assist in the diagnosis of rotator cuff impairment, such as cuff tears or tendinopathies, but there is controversy as to the accuracy and reliability of these tests (Itoi et al, 1997). The tests suggested

CORRESPONDENCE TO:

Annemarie Marais

244 Maroela Road, Centurion 0157

South Africa

Fax: +2712 354-1226

Tel: (012) 354-2023(w)

(012) 654-7785(h)

Cell: 0828131831

Email: amarais@postillion.up.ac.za are the empty can and full can tests for the integrity of the supraspinatus tendon; the lift off test for the intergrity of the subscapularis tendon and the lateral rotation test for the integrity of the infraspinatus muscle. The reader is referred to Table 1 for a detailed description of the tests, according to Kelly et a,1 (1996) \& Itoi et al, (1999).

Clark and Harryman (1992) proved that all four tendons fuse to form a common insertion on the tuberosities of the humerus. Fibres from both the subscapularis and infraspinatus muscles interdigitate with those of the supraspinatus muscle. This statement is supported by Itoi et a,l (1997), who confirmed that the posterior fibres of the supraspinatus merge with the oblique fibres of the infraspinatus tendon. Although the muscles blend at their insertions, each still has a separate movement function. Due to the complexity of the insertion, pathology in the one may compromise the vector of the other, resulting in rela- tive weakness in the unaffected muscle. This leads to the theory that pathology in a specific muscle has an influence on the biomechanical pull of the other and in so doing, influencing the accuracy of specific tests performed.

The purpose of this study was to investigate the reliability of the rotator cuff muscle tests and whether these tests can be used as diagnostic tools in general physiotherapy practice.

\section{METHODOLOGY}

A cross-sectional diagnostic study, of a descriptive nature, was performed at the Jacaranda Private Hospital in Pretoria during August and September 2003. A convenience sample test was used to collect the data. The patients were asked to complete a general information sheet to capture the inclusion and exclusion criteria.

The inclusion criteria included patients with unilateral shoulder pain who were diagnosed by means of ultrasonic imaging. Exclusion criteria included 
patients with bilateral shoulder pain and surgery to either of the shoulders in the past six months.

The data capturing sheet was designed in concurrence with the Department of Statistics at the University of Pretoria. The questions were adapted from two studies previously conducted by Kelly et al, (1996) and Itoi et al, (1999). The questionnaire was trail-tested on five subjects after which it was adapted to the current form. Data analysis of the study was done using frequency tables for the descriptive statistics and one or two way tables to test the relationships between the variables. Reliability of the four tests was tested according to sensitivity, specificity and the correlation with the doctor's diagnosis.

\section{Data collection}

After written informed consent was obtained, forty-five patients who met the inclusion criteria were assessed by means of the following tests: empty can, full can, lift off and external rotation,
(Table1). Both muscle strength and pain were noted. Grading is described in Tables 2 and 3 (adapted from Itoi et al, 1999). The researcher was blinded as to the diagnosis of the patients, avoiding bias that may have influenced the objectivity of the assessment. Thereafter the diagnoses made by the radiologist with ultrasound imaging, were compared to the results of the manual muscle testing.

The radiologist used the Bouffard classification (Bouffard et al, 2000) to make a diagnosis. The ultrasound examination was done with a Siemens Sonoline Elegra Ultrasound machine. High-resolution linear-array transducers were used with a broadband frequency capability between 7.5 - $9 \mathrm{MHz}$.

\section{Ethical considerations}

Participation in the study was voluntary and the patient signed an informed consent form before being included in the study. The Ethics committee of the University of Pretoria approved the study prior to the commencement of the evaluations.

\section{RESULTS AND DISCUSSION General results}

During August and September 2003, 52 patients presenting with unilateral shoulder pain at pre-selected orthopedic surgeons were assessed. The sample included 27 males and 25 females, ranging in age from 14 years to 79 years. Most of the patients included in the sample were older than 40 years of age $(85 \%)$.

\section{Results of rotator cuff muscle tests}

The results in this section are based on the results of the comparison between the doctor's diagnosis for a specific muscle and the manual muscle test described in the literature. The empty can, full can and external rotation tests all had about $50 \%$ correlation with the ultrasonic diagnosis of a muscle tear, while the lift off test had an $84 \%$ chance of misdiagnosing a muscle tear. The test was noted as a false positive, when the ultrasonic imaging indicated no tear in the muscle (although tendinopathy or calcification may have been present), but the manual

Table 1: Rotator cuff muscle tests adapted from Kelly et al. (1996) and Itoi et al. (1999).

\begin{tabular}{|c|c|c|c|}
\hline Empty can & Full can & Lift Off & External Rot. \\
\hline $\begin{array}{l}\text { The sitting patient's arm was } \\
\text { positioned in } 90 \text { ( of elevation } \\
\text { in the scapular plane and } \\
\text { full internal rotation of the } \\
\text { humerus. Resistance was } \\
\text { applied in a downward } \\
\text { direction and the patient } \\
\text { was asked to resist the } \\
\text { movement in correlation to } \\
\text { the resistance applied. }\end{array}$ & $\begin{array}{l}\text { The patient is positioned in } \\
\text { sitting. The arm is maintained } \\
\text { at } 90^{\circ} \text { of scapular elevation } \\
\text { and } 45^{\circ} \text { of external rotation } \\
\text { of the humerus. Resistance } \\
\text { was applied in a downward } \\
\text { direction and the patient } \\
\text { was asked to resist the } \\
\text { movement, in correlation to } \\
\text { the resistance applied. }\end{array}$ & $\begin{array}{l}\text { The sitting patient places the } \\
\text { arm behind his or her back } \\
\text { with the dorsum of the hand } \\
\text { resting in the midlumbar area. } \\
\text { The dorsum of the hand is } \\
\text { then raised from the back, } \\
\text { while maintaining a constant } \\
\text { elbow flexion angle. Internal } \\
\text { rotation is increased or } \\
\text { maintained, while extension } \\
\text { of the shoulder is increased. } \\
\text { Resistance was applied in a } \\
\text { posterior-anterior direction. }\end{array}$ & $\begin{array}{l}\text { The sitting patient was asked } \\
\text { to bend the elbows to } 90^{\circ} \\
\text { while maintaining zero } \\
\text { degrees of abduction. } \\
\text { The arm was then moved to } \\
45^{\circ} \text { of internal rotation. } \\
\text { Resistance is applied in an } \\
\text { inward direction }\end{array}$ \\
\hline
\end{tabular}

Table 2: Grading of manual muscle tests according to muscle strength adapted from Itoi et al. (1999).

\begin{tabular}{|l|l|l|}
\hline Grade & Resistance & Interpretation \\
\hline 4 & equal a mount of resistance to applied force (no movement) & N ormal \\
\hline 3 & $\begin{array}{l}\text { a mount of resistance less than (4), but force is still applied } \\
\text { (weakness in relation to other shoulder) }\end{array}$ & Partial thick= ness tear PTT \\
\hline 2 & ability to maintain position against gravity, no force applied & PTT \\
\hline 1 & $\begin{array}{l}\text { not able to hold against gravity if arm is moved passively } \\
\text { into the testing position }\end{array}$ & Full thickness tear (FTT) \\
\hline 0 & patient was not able to attain the required position & \\
\hline
\end{tabular}

A grading of 4 was regarded as a negative result, while 1, 2 and 3 were noted as positive.

A result of 0 was noted as an inability to perform the test. Both the symptomatic and asymptomatic arm was evaluated. 
muscle test indicated positive for pain and weakness. A test on the other hand was false negative when the ultrasonic diagnoses indicated a muscle tear but the manual muscle tests indicated no pain or muscle weakness. In all four tests the number of false positives far exceeded the number of false negatives, implying high sensitivity but low specificity.

\section{Supraspinatus tests}

Comparing the doctor's diagnosis in relation to a muscle tear and other pathologies e.g. tendinosis and calcifying tendonitis, with the result of the manual muscle test, (empty can test) the incidence of a correct diagnosis increased to $67 \%$. When this criterion is applied to the full can test the percentage increased to $61 \%$ (previously $51 \%$ ).
The false positive tests were compared to the other pathologies (calcifying tendonitis and tendinosis), the condition of the sub-acromial sub-deltoid (SASD) bursa, as well as the acromio-humeral distance. When considering the empty can test, most of the false positives were patients diagnosed with a decreased acromio-humeral distance i.e. less than $11 \mathrm{~mm}(61.90 \%)$. Fourteen percent of the patients suffered from a bursitis and only $4.76 \%$ had either a tendinosis or calcifying tendonitis. Only $14.3 \%$ of the patients diagnosed with a false positive had a normal muscle and tendon.

When considering the false positive results of the full can test, $5.26 \%$ of patients had a tendinosis; while $10.53 \%$ of patients had a SASD bursitis. Sixtythree percent of the patients diagnosed

Table 3: Grading of manual muscle tests according to pain adapted from Itoi et al. (1999)

\begin{tabular}{|l|l|}
\hline Grade & Amount of pain \\
\hline 4 & No pain \\
\hline 3 & Pain is present, but not limiting functionality \\
\hline 2 & Pain is a limiting factor to the muscle strength \\
\hline 1 & Muscle strength is severely limited by pain \\
\hline 0 & No movement possible due to pain \\
\hline
\end{tabular}

Table 4: Protocol for evaluation of rotator cuff muscle tests.

\begin{tabular}{|c|c|c|c|c|}
\hline & Empty can & Full can & Infraspinatus & Lift off \\
\hline 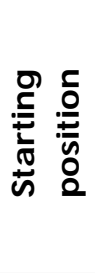 & $\begin{array}{l}\text { The patient is seated on } \\
\text { a plinth with the feet } \\
\text { supported, hips and knees } \\
\text { at } 90 \text { degrees of flexion, } \\
\text { without back support } \\
\text { (Itoi et al.: 1997). }\end{array}$ & $\begin{array}{l}\text { The same as for the "empty } \\
\text { can" test. (Itoi et al. : 1997). }\end{array}$ & $\begin{array}{l}\text { The same as for the "empty } \\
\text { can" test (Kelly et al.: 1996). }\end{array}$ & $\begin{array}{l}\text { The sitting patient places } \\
\text { the arm behind his } \\
\text { back with the dorsum of } \\
\text { the hand resting in the } \\
\text { midlumbar area } \\
\text { (Kelly et al.: 1996). }\end{array}$ \\
\hline : & $\begin{array}{l}\text { The patient is asked to } \\
\text { abduct the arm in the } \\
\text { scapular plane ( } 45 \text { degrees } \\
\text { of flexion) and maintain this } \\
\text { position while the arm is } \\
\text { internally rotated. } \\
\text { (Thumbs facing down) }\end{array}$ & $\begin{array}{l}\text { The patient is asked to } \\
\text { abduct the arm in the } \\
\text { scapular plane ( } 45 \text { degrees } \\
\text { of flexion) and maintain this } \\
\text { position while the arm is } \\
\text { externally rotated. } \\
\text { (Thumbs facing upwards) }\end{array}$ & $\begin{array}{l}\text { The patient is asked to } \\
\text { bend the elbows to } 90 \\
\text { degrees while maintaining } \\
\text { zero degrees of abduction. } \\
\text { The arm is then moved to } \\
45 \text { degrees of internal } \\
\text { rotation. }\end{array}$ & $\begin{array}{l}\text { The dorsum of the hand is } \\
\text { raised from the back, while } \\
\text { maintaining a constant } \\
\text { elbow flexion angle. } \\
\text { Internal rotation is increased } \\
\text { or maintained, while } \\
\text { extension of the shoulder } \\
\text { is increased. }\end{array}$ \\
\hline $\begin{array}{l}\bar{\pi} \\
\frac{\pi}{2} \\
\frac{\pi}{\Sigma}\end{array}$ & $\begin{array}{l}\text { Manual resistance is } \\
\text { applied to both the arms } \\
\text { at the elbows. Pain and } \\
\text { weakness are noted. }\end{array}$ & $\begin{array}{l}\text { Manual resistance is applied } \\
\text { to both the arms at the } \\
\text { elbows. Pain and weakness } \\
\text { are noted. }\end{array}$ & $\begin{array}{l}\text { Manual resistance is } \\
\text { applied at the wrists in an } \\
\text { inward direction. }\end{array}$ & $\begin{array}{l}\text { Manual resistance is applied } \\
\text { in a posterior- anterior } \\
\text { direction on the hand. }\end{array}$ \\
\hline$\underline{d}$ 트 & $\begin{array}{l}\text { The patient relaxes and } \\
\text { returns the arms to the sides. }\end{array}$ & $\begin{array}{l}\text { The patient relaxes and } \\
\text { returns the arms to the sides. }\end{array}$ & Return to starting position. & Return to starting position. \\
\hline
\end{tabular}

with a false positive, had a decreased subacromial space.

When considering a combination of pain and loss of muscle power (both areas scored a 3 or less) compared to the doctor's diagnosis (empty can test), no significant difference (53\% compared to $50 \%$ ), was noted. The test still only had a $53 \%$ chance of predicting a correct diagnosis, and the distribution of the false positives and negatives stayed the same. The same can be said for the full can test, where there was a $57 \%$ chance of a correct diagnosis when using the combination method.

The sensitivity for the empty can test was $76.1 \%$ and for the full can test $71.43 \%$. The latter, therefore has a slightly lower chance of predicting a tear in the muscle of the supraspinatus if a tear is present in the muscle. The full can test was slightly more specific than the empty can test ( $38.7 \%$ to $32.26 \%$ ).

From the literature (Kelly et al, 1996), it was expected that the empty can test would have a much higher incidence of false positive results than the full can test, due to the internal rotation of the arm. However, both tests had approximately a $50 \%$ chance of making a true or a false diagnosis. Although the empty can test is performed in the impinge- 
ment position (Rowe, 1988), which enlarges the subacromial space to some extent, it jams the supraspinatus tendon against the acromion. According to Ballantyne et al, (1993) the insertion of the supraspinatus muscle is moved out from underneath the acromial arch during external rotation of the arm.

Jobes and Moynes (1982) as well as Ballantyne et al, (1993) suggested the use of both pain and decreased muscle strength as an indicator of a positive test for rotator cuff tears. The results of this study show that neither one of these indicators, when used either alone, or in combination, are significantly superior when compared to the golden standard (doctor's diagnosis). Therefore, any one of these criteria may be used with equal power of predictability.

Patients diagnosed with a false positive result had a moderate incidence of other pathologies in the muscle. This may be helpful in explaining the high number of false positive results. According to Andrews and Wilk (1994) calcifying tendonitis may cause pain due to a functional narrowing of the subacromial space, therefore influencing the muscle strength through pain inhibition. The same applies to a patient with either a bursitis or a tendinosis. This further correlates with the findings of Ballantyne et al, (1993) and Andrews and Wilk (1994), which state that pain during the test influences the reliability of the test.

\section{Subscapularis test}

The lift off test only demonstrated a $15 \%$ chance of predicting the correct diagnosis for the subscapularis muscle. The rate of false positives was very high and accounted for the other $85 \%$ of the sample. Taking the doctor's diagnosis (normal or abnormal muscle) the results improved to $54 \%$ false positives and a $47 \%$ chance of making the correct diagnosis.

No false negatives were scored. Sixty percent of the false positives were diagnosed with a decreased acromiohumeral space while $5 \%$ of the patients had a tendonitis. However, only $16 \%$ of the patients who tested as false positive had a bursitis of the SASD bursa. Seven percent of the patients presented with a normal muscle and tendon.
If the criteria for a positive test are based on the general condition of the muscle, then the amount of false positives decreases drastically from 44 patients to 25 patients. Nineteen of the patients are then correctly diagnosed with pathology to the subscapularis. The combination criteria also made a difference to the result; an increase of $100 \%$ was noted for giving the same diagnosis as the doctor (16 compared to a previous 8 ), therefore the amount of false positives decreased from $10 \%$ to $70 \%$. The sensitivity of this specific test is very high $(100 \%)$, but the specificity, is very low (10.2\%).

The lift off test was performed in accordance with specifications as described by Greis et al, (1996). In the total sample of 52 patients only three were diagnosed with a tear to the subscapularis muscle. This is supported by the statistics in a study conducted by Greis et al, (1996).

The characteristics of the lift off test include extreme internal rotation of the arm in order to exclude the pectoralis major from the test through passive insuffiency; this once again results in the test being performed in the impingement position. A very high frequency of false positive results was present (44/52). Out of a possible 52 patients, 39 patients however suffered from a bursitis of the SASD bursa and 32 of the patients were diagnosed with a decreased acromiohumeral space, and a combination of pathologies including calcifying tendonitis. Therefore, a relationship between a false positive result and a bursitis or a change in the subacromial space may be suggested.

If a combination of pain and muscle strength, or pain alone, is used to evaluate the patients, the reliability of the test increases drastically. However, evaluating the muscle on pain alone may lead to another false positive result due to the high incidence of bursitis in the false positive group and low incidence of actual muscle tears in this sample group.

No false negative results were noted; this may be due to the fact that the test is already difficult to perform due to the starting position and that the patients with a tear of the subscapularis muscle would most likely not be able to perform the desired action. Furthermore, the sensitivity of the test is $100 \%$, implying that a patient with the pathology would definitely test positive. The low values for the specificity and accuracy could be attributed to the large influence that a bursitis has on the result of the test, which in turn can be related to the position of the arm.

From the above statements it can be concluded that, although the test is very sensitive for pathology in the muscle, another test may be more specific for identifying a tear with a higher accuracy if the painful starting position can be eradicated.

\section{Infraspinatus test}

The manual muscle test relating to the integrity of the muscle has a $47 \%$ chance of predicting the correct diagnosis when compared to the doctor's diagnosis. When compared to the general condition of the muscle, this decreases to $44 \%$. Forty percent of the patients were diagnosed with a false positive result. Most of these patients presented with a decreased subacromial space $(70.37 \%)$. Fifteen percent of the false positive patients suffered from a bursitis of the SASD bursa. Fifteen percent of the false positive group had a normal muscle and tendon. The sensitivity of the test is high (80\%), but the specificity low $(42.55 \%)$.

Once again the high frequency of other pathologies in the false positive group indicates that they play a role in the reliability of the test. When discussing the relationship between the doctor's diagnosis on the general condition of the tendon and the result of the muscle test, it does not make a great difference to the reliability of the test if it were designed to detect any pathology to the tendon. This may be due to the fact that the SASD bursa plays a role in all the tests, but is not considered a part of any of these muscles. This test is not performed in the impingement position, although muscle contraction may have an effect on the SASD bursa through increased tendon pressure.

The sensitivity of this test for pathology in the infraspinatus muscle is high. This leads to the conclusion that a patient with a tear in the infraspinatus muscle would have decreased muscle 
strength most of the time, but the low specificity implies that weakness is not necessarily an indicator of a tear to the muscle.

\section{Pain and rotator cuff pathology}

In literature pain is listed as one of the main symptoms of rotator cuff pathologies (Souza,1994). This is supported by the results of the relationship between the doctor's diagnosis for supraspinatus and the pain experienced by the patient (empty can and full can tests). Twentyseven $(80 \%)$ of the patients experiencing pain were diagnosed with pathology of the muscle, however when the relationship to tears of the muscle is considered, this advantage is lost; 20 of the 37 patients experiencing pain did not have a tear to the muscle.

When comparing the empty can test with the full can test in relation with the pain experienced by the patient, $50 \%$ of the patients experienced no pain during both tests and $17 \%$ only slight pain.

Several patients stated that the starting position of the test is a painful position when asked to move the arm to the starting position, adding a subjective inhibition to the test. It is interesting to note that a number of patients found it very difficult to perform the test with the healthy arm, not due to pain or perceived weakness (by the patient), but due to lack of understanding and ability to perform the action. This may influence the reliability of the test since the pathological shoulder has pain inhibition to overcome as well as the lack of skill.

\section{CONCLUSION}

Although the manual muscle tests were designed to detect a torn muscle, other factors do play a role e.g., SASD bursitis and a decreased acromio humeral space. The main influence of these factors is due to pain during movement or muscle contraction, thereby functionally narrowing the subacromial space and causing a possible decrease in muscle power due to pain. A decrease in muscle strength would result in a false positive test indicating a torn muscle even when the muscle is intact.

The reliability of the evaluated tests was not as high as expected. The sensitivity of these tests is high, although the specificity is low. The results of the study suggest that this could be attributed to several factors influencing muscle strength through pain e.g. decreased acromiohumeral space or a SASD bursitis.

By definition a manual muscle test is only positive when an asymmetry is found between the affected muscle and the opposite side in relation to muscle strength. However, the correlation with the doctor's diagnosis increased when pain alone or pain as well as muscle strength were used as criteria. Therefore, the author would recommend the use of both during an evaluation.

Two tests for the supraspinatus were evaluated in this study. Although the full can test performed slightly better according to all the criteria, it was not significant, and therefore both the tests can be used as a diagnostic tool in the evaluation of the integrity of the supraspinatus tendon.

The low correlation with doctor's diagnosis must however be noted and considered when making a diagnosis. This implies that, although the test is positive, it may indicate a different pathology and not necessarily a tear to the muscle.

The results of this study show an even higher correlation with the results of the sonography when any pathology of the muscle is considered as the criteria for the tests as opposed to a muscle tear alone From this follows the conclusion that the tests may be better suited to detect if pathology if present within the muscle and not a tear to the muscle as such.

While these manual muscle tests are used in general practice to diagnose tears of the rotator cuff muscles, they may not be as accurate and reliable as has previously been assumed (Donatelli, 1991; Kelly et al, 1996;Greis et a,1 1996). Further studies with a bigger sample group to verify this statement is recommended. The tests may still be valuable to act as a preliminary diagnosis, however, they should be used as part of an integrated evaluation and not as the gold standard.

The study was limited mainly due to the following factors:

- A limited period in which to complete the study, which influenced the size of the sample group.
The author would like to make the following recommendations for further research in the field:

- A bigger sample group with a wider distribution between the age groups.

- Comparison between different tests for the subscapularis as well as the infraspinatus muscle.

- Including the biceps tendon as one of the pathologies that may influence the results of the test.

- Comparing the manual muscle tests with Magnetic Resonance Imaging (MRI), which is postulated to be a more accurate test than ultrasound.

\section{REFERENCES}

Andrews JR, Wilk KE 1994 The Athlete's Shoulder. New York: Churchill Livingston.

Ballantyne BT, O'Hare SJ, Paschall JL, Pavia-Smith MM, Pitz AM, Gillon, JF, Soderberg GL. 1993 Electomyographic activity of selected shoulder muscles in commonly used therapeutic exercises. Physical Therapy. 73(10) October: 668-681

Bouffard JA, Lee S, Dhanju J 2000 Ultrasonography of the shoulder. Seminars in Ultrasound, CT and MRI. 21(3): 164-191

Clark JM, Harryman DT, 1992 Tendons ligaments and capsule of the rotator cuff gross and microscopic anatomy. Journal of Bone and Joint Surgery. 74A(5): 713-725

Greis PE, Kuhn JE, Schultheis J, Hintermeister R, Hawkins R 1996 Validation of the Lift-off Test and Analysis of Subscapularis Activity During Maximal Internal Rotation. The American Journal of Sports Medicine 24 (5): 589-5 93

Itoi E, Minagawa H, Sato T, Sato K, Tabata S 1997 Isokinetic Strength after Tears of the Supraspinatus Tendon. The Journal of Bone and Joint Surgery 79B(1) January: 77-82

Itoi E, Kido T, Sano A, Urayama M, Sato K 1999 Which is More Useful, the "full can" test or the "empty can" test in Detecting the Torn Supraspinatus Tendon? The American Journal of Sports Medicine 27(1): 65-68

Jobe FW, Moynes, DR 1982 Delineation of diagnostic criteria and a rehabilitation programme for rotator cuff injuries. The American Journal of Sports Medicine 10(6): 336-339

Kelly BT, Kadrmas WR, Speer KP 1996 The Manual Muscle Examination for Rotator Cuff Strength. The American Journal of Sports Medicine 24(5): 581-588

Rowe CR 1988 The Shoulder. New York: Churchill Livingstone

Thompson WA, Debski RE, Boardman ND, Taskiran E, Warner JJP, Fu FH, Woo SL 1996 A Biomechanical Analysis of Rotator Cuff Deficiency in a Cadaveric Model. The American Journal of Sports Medicine 24(3): 286-292 


\section{REUABIUTY OF ROTATOR CUFF MUSCLE DIAGNOSTIC TESTS}

Please answer each question by drawing a circle $(0)$ around a number in a shaded box or by writing your answer into the shaded space provided

Patient number

v1

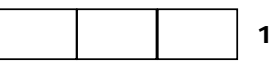

1. W hat is your age in completed years?

2. W hat is your gender?

\begin{tabular}{|l|l|}
\hline Male & $\mathbf{1}$ \\
\hline Female & $\mathbf{2}$ \\
\hline
\end{tabular}

3. Have you injured a shoulder prior to this visit?

\begin{tabular}{|l|l|}
\hline Left shoulder & $\mathbf{1}$ \\
\hline Right shoulder & $\mathbf{2}$ \\
\hline Left and Right shoulder & $\mathbf{3}$ \\
\hline
\end{tabular}

4. Which shoulder is painful now?

\begin{tabular}{|l|l|}
\hline Left & $\mathbf{1}$ \\
\hline Right & $\mathbf{2}$ \\
\hline
\end{tabular}

5. Are you on medication for the present shoulder pain?

\begin{tabular}{|l|l|}
\hline Yes & $\mathbf{1}$ \\
\hline No & $\mathbf{2}$ \\
\hline
\end{tabular}

6. If you answered "Yes" in Question $\mathbf{5}$ above, what medication are you using?

\begin{tabular}{|l|l|}
\hline Pain killers & $\mathbf{1}$ \\
\hline Anti-inflammatory & $\mathbf{2}$ \\
\hline Pain killers and anti-inflammatory & $\mathbf{3}$ \\
\hline
\end{tabular}

7. Do you experience loss of function?

\begin{tabular}{|l|l|}
\hline Yes & $\mathbf{1}$ \\
\hline No & $\mathbf{2}$ \\
\hline
\end{tabular}

8. If you answered "Yes" to Question 7 above, please indicate the area of dysfunction.

\begin{tabular}{|l|l|}
\hline Sleeping & $\mathbf{1}$ \\
\hline Dressing & $\mathbf{2}$ \\
\hline Lifting of arm above the shoulder & $\mathbf{3}$ \\
\hline O ther (specify): & \\
\hline
\end{tabular}

9. W hich hand is your dominant hand?

\begin{tabular}{|l|l|}
\hline Left & $\mathbf{1}$ \\
\hline Right & $\mathbf{2}$ \\
\hline
\end{tabular}

V2

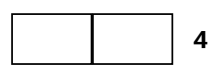

V3

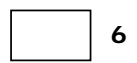

V4

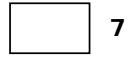

V5

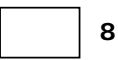

V6

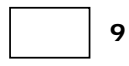

v7

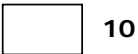

v8
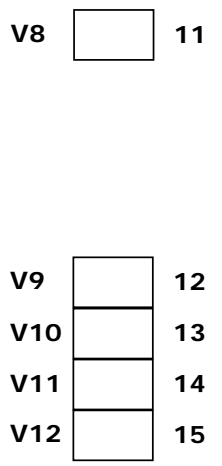

V13 16 
10. Empty Can - Manual

\begin{tabular}{|l|l|l|l|l|l|}
\hline Strength Left & $\mathbf{4}$ & $\mathbf{3}$ & $\mathbf{2}$ & $\mathbf{1}$ & $\mathbf{0}$ \\
\hline Strength Right & $\mathbf{4}$ & $\mathbf{3}$ & $\mathbf{2}$ & $\mathbf{1}$ & $\mathbf{0}$ \\
\hline Pain Left & $\mathbf{4}$ & $\mathbf{3}$ & $\mathbf{2}$ & $\mathbf{1}$ & $\mathbf{0}$ \\
\hline Pain Right & $\mathbf{4}$ & $\mathbf{3}$ & $\mathbf{2}$ & $\mathbf{1}$ & $\mathbf{0}$ \\
\hline
\end{tabular}

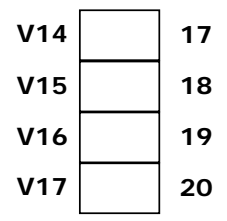

11. Full Can - Manual

\begin{tabular}{|l|l|l|l|l|l|}
\hline Strength Left & $\mathbf{4}$ & $\mathbf{3}$ & $\mathbf{2}$ & $\mathbf{1}$ & $\mathbf{0}$ \\
\hline Strength Right & $\mathbf{4}$ & $\mathbf{3}$ & $\mathbf{2}$ & $\mathbf{1}$ & $\mathbf{0}$ \\
\hline Pain Left & $\mathbf{4}$ & $\mathbf{3}$ & $\mathbf{2}$ & $\mathbf{1}$ & $\mathbf{0}$ \\
\hline Pain Right & $\mathbf{4}$ & $\mathbf{3}$ & $\mathbf{2}$ & $\mathbf{1}$ & $\mathbf{0}$ \\
\hline
\end{tabular}

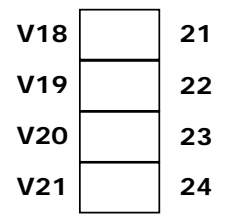

12. Lift off - Manual

\begin{tabular}{|l|l|l|l|l|l|}
\hline Strength Left & $\mathbf{4}$ & $\mathbf{3}$ & $\mathbf{2}$ & $\mathbf{1}$ & $\mathbf{0}$ \\
\hline Strength Right & $\mathbf{4}$ & $\mathbf{3}$ & $\mathbf{2}$ & $\mathbf{1}$ & $\mathbf{0}$ \\
\hline Pain Left & $\mathbf{4}$ & $\mathbf{3}$ & $\mathbf{2}$ & $\mathbf{1}$ & $\mathbf{0}$ \\
\hline Pain Right & $\mathbf{4}$ & $\mathbf{3}$ & $\mathbf{2}$ & $\mathbf{1}$ & $\mathbf{0}$ \\
\hline
\end{tabular}

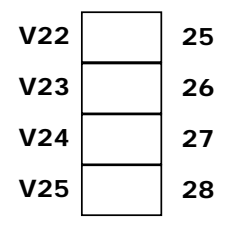

\section{External Rotation - Manual}

\begin{tabular}{|l|l|l|l|l|l|}
\hline Strength Left & $\mathbf{4}$ & $\mathbf{3}$ & $\mathbf{2}$ & $\mathbf{1}$ & $\mathbf{0}$ \\
\hline Strength Right & $\mathbf{4}$ & $\mathbf{3}$ & $\mathbf{2}$ & $\mathbf{1}$ & $\mathbf{0}$ \\
\hline Pain Left & $\mathbf{4}$ & $\mathbf{3}$ & $\mathbf{2}$ & $\mathbf{1}$ & $\mathbf{0}$ \\
\hline Pain Right & $\mathbf{4}$ & $\mathbf{3}$ & $\mathbf{2}$ & $\mathbf{1}$ & $\mathbf{0}$ \\
\hline
\end{tabular}

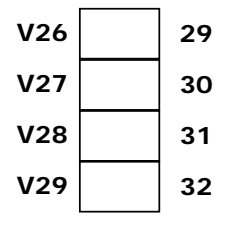

14. Doctor's diagnosis - Muscles

\begin{tabular}{|l|c|c|}
\hline \multicolumn{1}{|c|}{ Muscle } & Normal & Abnormal \\
\hline Supraspinatus & $\mathbf{1}$ & $\mathbf{2}$ \\
\hline Subscapularis & $\mathbf{1}$ & $\mathbf{2}$ \\
\hline Infraspinatus & $\mathbf{1}$ & $\mathbf{2}$ \\
\hline
\end{tabular}

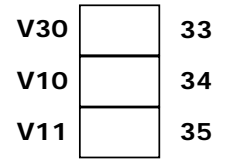

15. Doctor's diagnosis - Tear thickness

\begin{tabular}{|l|c|c|c|}
\hline \multicolumn{1}{|c|}{ Muscle } & Full tear & Partial tear & No tear \\
\hline Supraspinatus & $\mathbf{1}$ & $\mathbf{2}$ & $\mathbf{3}$ \\
\hline Subscapularis & $\mathbf{1}$ & $\mathbf{2}$ & $\mathbf{3}$ \\
\hline Infraspinatus & $\mathbf{1}$ & $\mathbf{2}$ & $\mathbf{3}$ \\
\hline
\end{tabular}

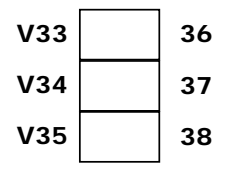

16. Doctor's diagnosis - Calcification/ Tendinopathy

\begin{tabular}{|l|c|c|c|c|}
\hline \multicolumn{1}{|c|}{ Muscle } & Calcification & Tendinopathy & Both & None \\
\hline Supraspinatus & $\mathbf{1}$ & $\mathbf{2}$ & $\mathbf{3}$ & $\mathbf{4}$ \\
\hline Subscapularis & $\mathbf{1}$ & $\mathbf{2}$ & $\mathbf{3}$ & $\mathbf{4}$ \\
\hline Infraspinatus & $\mathbf{1}$ & $\mathbf{2}$ & $\mathbf{3}$ & $\mathbf{4}$ \\
\hline
\end{tabular}

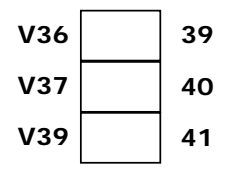

17. Doctor's diagnosis SASD Bursa

\begin{tabular}{|l|l|}
\hline Normal & $\mathbf{1}$ \\
\hline Bursitis & $\mathbf{2}$ \\
\hline
\end{tabular}

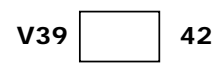

18. Doctor's diagnosis Acromio-humeral distance

\begin{tabular}{|l|l|}
\hline Greater than $11 \mathrm{~mm}$ & $\mathbf{1}$ \\
\hline $8 \mathrm{~mm}$ to $11 \mathrm{~mm}$ & $\mathbf{2}$ \\
\hline Less than $8 \mathrm{~mm}$ & $\mathbf{3}$ \\
\hline
\end{tabular}

